\title{
Application of Fuzzy Borda Combination Evaluation in Subjective and Objective Evaluation Methods in Comprehensive Evaluation of Population Development
}

\author{
Jiajia $\mathrm{Yu}^{1}$, Hongqi $\mathrm{Ma}^{2}$ and Yuqi $\mathrm{Han}^{3, *}$ \\ ${ }^{1}$ Construction Management and Real estate Department, Chongqing JianZhu College, Chongqing, China \\ ${ }^{2}$ Agricultural Economics Department, China Agricultural University, Beijing, China \\ ${ }^{3}$ Construction Management and Real estate Department, Chongqing JianZhu College, Chongqing, China \\ Corresponding author: 43222240@qq.com
}

\begin{abstract}
This paper constructs the comprehensive index evaluation of population development from the three aspects of human development, population and economic society and population, resources and environment, according to the movement course and changing trend of population development at home and abroad, and the guiding ideology of national population development strategy system. The index system consists of 3 first level indexes, 8 Secondary indexes,22 tertiary level indexes and 42 fourth level indexes.And on the basis of commonly used comprehensive evaluation methods. The comprehensive evaluation of the population development in China in 2013 was made by using the combined evaluation method, which effectively overcomes the shortcomings of the objective evaluation method and the subjective evaluation method, and obtains a more credible comprehensive evaluation value.
\end{abstract}

\section{Introduction}

China is the world's most populous country. The US Bureau of Population and Human Services published the 2010 WORLD POPULATION in July 2010 DATA SHEET "shows that in the foreseeable 2050 China will be 1.437 billion population to become second only to India, the world's second most populous country [1]. Population has always been China to consider all the problems of the starting point and end point, the population problem is always a key factor restricting the development of sound and fast. As the most populous developing country in the world, by the 1950 s to encourage childbearing and 70 years after the birth control of the population policy of the two major impact in less than 30 years, the population reproduction type from the "high birth, low death, high Growth "to" low birth, low death, low growth. " The change of the type of population reproduction in western developed countries is the natural result of economic and social development and modernization; the main body of population development as modernization is the realization of the modernization of economy and society. Modernization process. In the past 30 years of reform and opening up, industrialization,marketization,urbanization,informatization and economic globalization have promoted China's rapid economic and social development. In the past 30 years, China's industrialization and marketization, urbanization, informationization and economic globalization have promoted China's rapid economic and social progress. In the transitional period, the population development lags behind the economic and social development and faces an unprecedented complex situation. Population quality, the transfer of rural surplus labor force, the problem of population mobility, the problem of young labor shortage, population aging, population poverty, social security, gender imbalance, the one-child problem, population development and economic society, resource and environment And many other problems appear. The national population development strategy put forward: Adhere to the people-oriented, give priority to investment in the comprehensive development of human beings, realize the transition from the big population to the powerful country of human capital and realize the coordination and sustainable development of the population and the economic and social resources and environment. The 11th Five-Year Plan for Population Development and the 2020 Plan clearly defined the guiding ideology of population development: "With Deng Xiaoping Theory and the important thinking of the 'Three Represents' as the guide, comprehensively implement the scientific concept of development, adhere to the requirements of building a harmonious socialist society, People-oriented, promote institutional innovation, give priority to investment in the overall development of the people. Stable low fertility, improve the quality of population, improve population structure, guide the population reasonable distribution, guarantee population security .Promotional population to the human capital power transformation, promote population and economy, Social, resource, environmental coordination and sustainable development. "The implementation of population development strategies and plans requires a scientifically constructed population development monitoring 
system to ensure the accuracy and effectiveness of the underlying statistical sources. It is worth noting that population development includes not only the total population and the growth of the scale, more importantly, the quality of the population, the natural environment of population activities and the improvement of the social environment. The monitoring of population development includes not only the monitoring of total population, but also the monitoring of relevant factors such as population health quality, cultural quality, population structure, population movement, economic activities of population, living environment and so on. Therefore, population development monitoring is an ambitious and complex system engineering. It not only needs to integrate the statistical path of demographic development data source, but also needs to construct a scientific and reasonable comprehensive evaluation system and monitoring model. Through the computer network system, The population monitoring objectives, to ensure that the authority of the decision-making of the population of the scientific and accurate; At the same time for the academic community in-depth study of China's population problems, revealing China's population quantity, quality, structure, mobility, and population economic activities, People and the natural environment and other inherent laws to provide a real and reliable data source; also for enterprises to predict the market, to provide decision-making reference.

\section{Index system}

Based on the study of population development both at home and abroad, this paper aims to promote the construction of the evaluation system of population development from the theoretical and practical perspectives. According to population size, population quality, population and economic society and population, resource and environment, four comprehensive evaluation methods of population development are constructed. The four comprehensive evaluation methods of principal component analysis, factor analysis, entropy and expert scoring are used respectively. Finally, the composite evaluation method was applied to evaluate the four comprehensive evaluation results, and the comprehensive evaluation results were obtained.

\subsection{Comprehensive evaluation index system of China 's population development}

From the connotation of population development, this paper makes an investigation on the indicators of population development in various functional departments (statistics, public security, development and reform, population and family planning, labor and social security, civil affairs, education, health, resources, transportation and other sectors) A total of more than 200, according to the basic principles of the index system to build the screening indicators, to build a comprehensive population evaluation index system, including the population of its own development index system, population and economic and social indicators system, population and resources and environmental indicators system three sub- system [4].

The comprehensive evaluation system of population development includes three indicators: population selfdevelopment, population and economic society [5], population and resource and environment index system, and secondary index system 8 (population size, population structure, population quality, population distribution, population and population). Economy, population and society, population and resources, population and environment); 22 index system of level 3; 42 index system of 4 levels in Table1.

Table 1.Population evaluation index system.

\begin{tabular}{|c|c|c|c|}
\hline $\begin{array}{l}\text { Level } \\
\text { indicators } \\
(3)\end{array}$ & $\begin{array}{l}\text { two indicators } \\
(8)\end{array}$ & three indicators $(22)$ & four indicators (42) \\
\hline \multirow{10}{*}{$\begin{array}{l}\text { Population self } \\
\text { - development } \\
\text { indicator } \\
\text { system }\end{array}$} & \multirow{4}{*}{ Population size } & $\begin{array}{l}\text { Population total fertility rate } \\
\text { (person) }\end{array}$ & $\begin{array}{c}\text { Population total fertility rate } \\
\text { (person) }\end{array}$ \\
\hline & & $\begin{array}{c}\text { Natural population growth rate } \\
(\%)\end{array}$ & $\begin{array}{c}\text { Natural population growth rate } \\
(\%)\end{array}$ \\
\hline & & Birth rate $(\%)$ & Birth rate $(\%)$ \\
\hline & & Mortality (\%o) & Mortality $(\% o)$ \\
\hline & \multirow{6}{*}{$\begin{array}{c}\text { Population } \\
\text { Quality }\end{array}$} & Average life expectancy (years) & Average life expectancy (years) \\
\hline & & $\begin{array}{c}\text { Public health expenditure per } \\
\text { unit GDP (\%) }\end{array}$ & $\begin{array}{l}\text { Public health expenditure per unit } \\
\text { GDP }(\%)\end{array}$ \\
\hline & & $\begin{array}{c}\text { Expenditure on Educational } \\
\text { Expenditure per Unit of GDP } \\
(\%)\end{array}$ & $\begin{array}{c}\text { Expenditure on Educational } \\
\text { Expenditure per Unit of GDP }(\%)\end{array}$ \\
\hline & & Literacy rate $(\%)$ & Adult literacy rate \\
\hline & & $\begin{array}{l}\begin{array}{l}\text { Average years of schooling } \\
\text { (years) }\end{array} \\
\text { (yers }\end{array}$ & 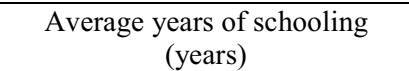 \\
\hline & & $\begin{array}{l}\text { The number of scientific and } \\
\text { technical personnel per } 10,000\end{array}$ & $\begin{array}{c}\text { population (person) the average } \\
\text { number of scientific and }\end{array}$ \\
\hline
\end{tabular}




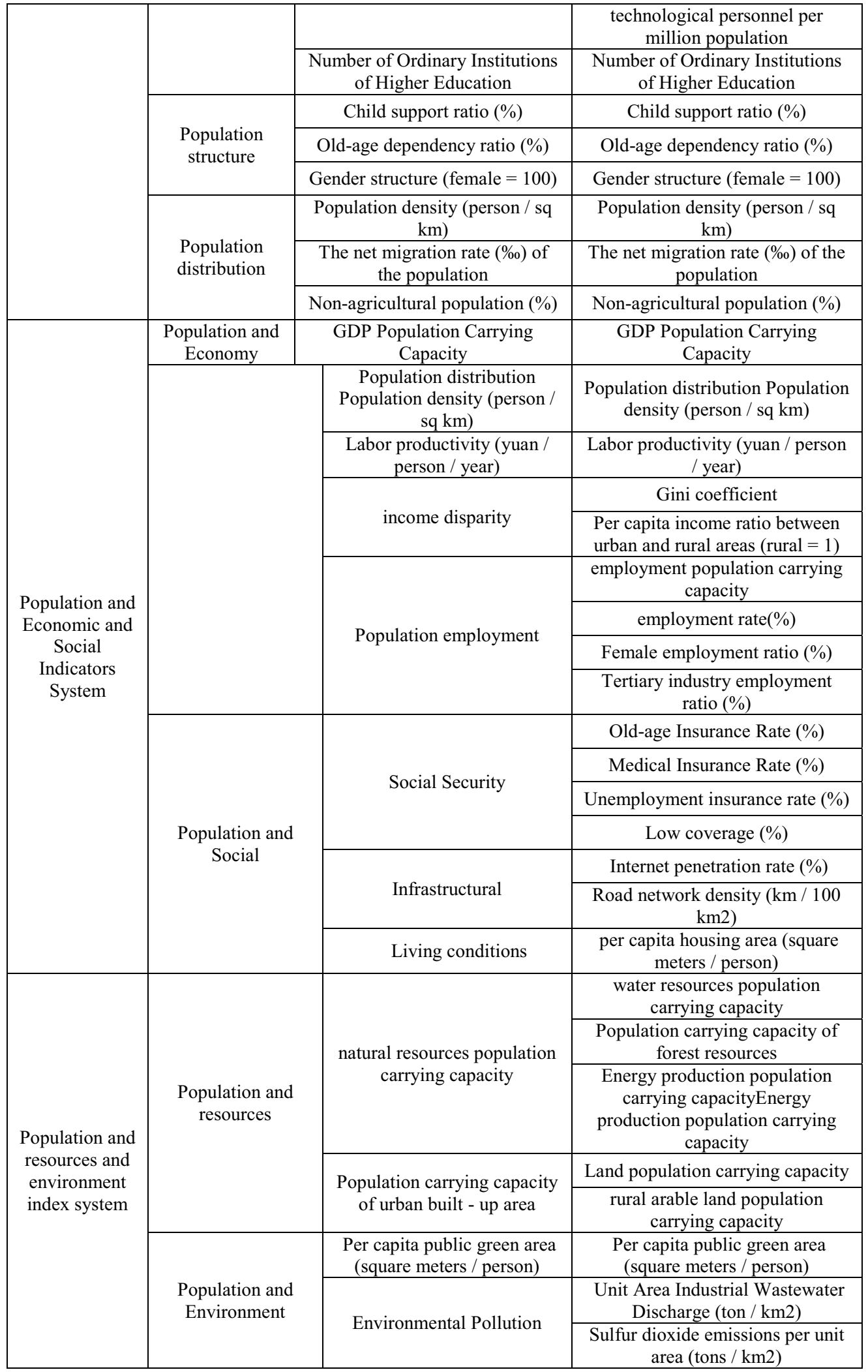




\subsection{Multi - level combination evaluation model}

This paper attempts to construct a multi-level combination evaluation model:

The first step is to use representative principal component analysis, factor analysis and entropy method as the objective weighting method, using the expert scoring method as the subjective weighting method, respectively, to make a comprehensive evaluation of population development, and lists the different evaluation . The results of the evaluation of the method were compared for comparison. The second step, according to the results of the comprehensive evaluation of portfolio evaluation, and finally give the comprehensive development of population evaluation value [2].

Combined evaluation method is a comprehensive evaluation method in which a variety of evaluation methods can not draw a convincing and unanimous conclusion, and then use a variety of evaluation methods to conduct a comprehensive evaluation of the same evaluation object or the same index system, and then according to the ranking of each comprehensive evaluation. The results of a combination sorts an evaluation method. The methods of sorting the various combinations are: average method, Borda method, Copeland method, fuzzy Borda method. The combination of fuzzy Borda method and the Borda method and Copeland method only consider the difference of the sorting order of the evaluation results, which is based on the difference of the scores and the ranking difference of each method. Therefore, fuzzy Borda combination evaluation method is relatively more scientific. The final combination results of this project are based on the fuzzy Borda combination evaluation method. The combination of fuzzy Borda method is: [6]

1.calculate the membership

Membership refers to the evaluation of a certain object in the evaluation object in the "superior" membership, assuming membership for $U_{i j}$, then

$$
U_{i j}=\frac{z_{i j}-\min \left\{z_{i j}\right\}}{\max \left\{z_{i j}\right\}-\min \left\{z_{i j}\right\}}, i=1,2, \ldots, p
$$

$z_{i j}$ is the comprehensive evaluation value of the $\mathrm{i}$-th evaluation scheme under the condition of the $\mathrm{j}$-th evaluation method.

2.Fuzzy frequency calculation

Fuzzy frequency is mainly used to reflect the difference of comprehensive evaluation value. According to membership degree can calculate the fuzzy frequency[2]

$$
f_{i h}=\sum_{R=1}^{m} \sigma_{i h} U_{i j}
$$

$\sigma_{i h}=\left\{\begin{array}{l}1 \\ 0\end{array}\right.$ (When the first $\mathrm{i}$ kind of evaluation scheme in a certain evaluation method ranked $\mathrm{h}$, the value is 1 , otherwise 0 ). Then the fuzzy frequency is

$$
p_{i h}=\frac{f_{i h}}{\sum f_{i h}}
$$

3.The ranking order of the evaluation object which is derived from the comprehensive evaluation is converted into the scoring form

$$
S_{h}=\frac{(n-h)(n-h+1)}{2}
$$

$S_{h}$ represents the score, and $h$ represents the ranking order.

4.Calculate the fuzzy Borda values. The formula is

$$
B_{i}=\sum P_{i h} S_{i h}
$$

$B_{i}$ is Fuzzy Borda number.

\section{Solving}

In order to obtain the final comprehensive evaluation result of population development, and to make full use of the advantages of various evaluation methods to reduce the errors caused by its shortcomings, this paper adopts the fuzzy Borda combination evaluation method on the basis of the four kinds of comprehensive evaluation and sorting results.

Based on the data of the 2013 index data, the population development of China is evaluated. Firstly, comparing the differences of the four comprehensive evaluation methods, principal component analysis, factor analysis, entropy and expert scoring methods, in principle, the degree of difference of all kinds of comprehensive evaluation methods can not be too large, otherwise, the combination evaluation significance. In this paper, spearmen rank correlation coefficient to test a variety of comprehensive evaluation results of the degree of association, spearmen rank correlation coefficient is: [7] 


$$
r_{p s}=1-\frac{6 \sum_{t=1}^{n}\left(P_{t}-S_{t}\right)^{2}}{n\left(n^{2}-1\right)}
$$

$r_{p t}$ is the relationship between the ${ }^{p}$ th comprehensive evaluation method and the $t_{\text {th }}$ comprehensive evaluation

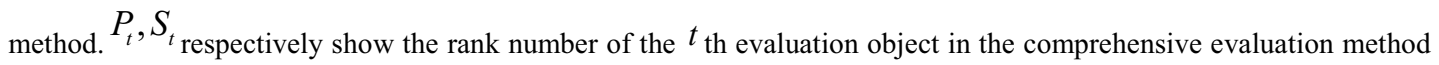
of the $p$ type and the $S$ type. ${ }^{n}$ represents the number of objects to be evaluated. Accordingly, the spearmen rank correlation coefficient matrices of four comprehensive evaluation methods are shown in Table 2.

Table 2. Spearmen 's Rank Correlation Coefficient Matrix of Four Comprehensive Evaluation Methods.

\begin{tabular}{|c|c|c|c|c|}
\hline & $\begin{array}{c}\text { Principal } \\
\text { compone } \\
\text { nt } \\
\text { analysis }\end{array}$ & $\begin{array}{c}\text { factor } \\
\text { analysi } \\
\mathrm{s}\end{array}$ & $\begin{array}{c}\text { entropy } \\
\text { weightin } \\
\mathrm{g}\end{array}$ & $\begin{array}{c}\text { expert } \\
\text { scorin } \\
\mathrm{g}\end{array}$ \\
\hline $\begin{array}{c}\text { Principal } \\
\text { compone } \\
\text { nt } \\
\text { analysis }\end{array}$ & 1 & 0.774 & 0.818 & 0.782 \\
\hline $\begin{array}{c}\text { factor } \\
\text { analysis }\end{array}$ & 0.774 & 1 & 0.942 & 0.894 \\
\hline $\begin{array}{c}\text { entropy } \\
\text { weightin } \\
\text { g }\end{array}$ & 0.818 & 0.942 & 1 & 0.921 \\
\hline $\begin{array}{c}\text { expert } \\
\text { scoring }\end{array}$ & 0.782 & 0.894 & 0.921 & 1 \\
\hline
\end{tabular}

According to the spearmen correlation coefficient matrix of the four comprehensive evaluation methods in Table 2, the four comprehensive evaluation methods all have a high degree of association, and are suitable for combinatorial analysis.

In this paper, fuzzy Borda combination evaluation method is used to do comprehensive evaluation on four comprehensive evaluation methods of principal component analysis, factor analysis, entropy and expert scoring, and the fuzzy Borda combination evaluation value and ranking are obtained in 2013 in Table3.

Table 3.Comprehensive Evaluation and Ranking of Population Development Based on Fuzzy Borda Combination Evaluation $[3,8]$

\begin{tabular}{|c|c|c|c|c|c|c|c|c|c|c|}
\hline & \multicolumn{2}{|c|}{$\begin{array}{c}\text { Principal } \\
\text { component analysis }\end{array}$} & \multicolumn{2}{|c|}{ factor analysis } & \multicolumn{2}{c|}{ entropy weighting } & \multicolumn{2}{c|}{ expert scoring } & \multicolumn{2}{c|}{$\begin{array}{c}\text { Fuzzy Borda } \\
\text { Combination } \\
\text { Evaluation }\end{array}$} \\
\hline $\begin{array}{c}\text { Serial } \\
\text { number }\end{array}$ & Area & $\begin{array}{c}\text { Integra } \\
\text { ted } \\
\text { value }\end{array}$ & Area & $\begin{array}{c}\text { Integr } \\
\text { ated } \\
\text { value }\end{array}$ & Area & $\begin{array}{c}\text { Integ } \\
\text { rated } \\
\text { value }\end{array}$ & Area & $\begin{array}{c}\text { Integr } \\
\text { ated } \\
\text { value }\end{array}$ & Area & $\begin{array}{c}\text { Integra } \\
\text { ted } \\
\text { value }\end{array}$ \\
\hline 1 & Beijing & 0.16 & Beijing & 1.43 & Beijing & 0.72 & Beijing & 0.69 & Beijing & 435 \\
\hline 2 & Shanghai & 0.16 & Shanghai & 1.22 & Shanghai & 0.69 & Shanghai & 0.63 & Shanghai & 406.0 \\
\hline 3 & Jilin & 0.11 & Tianjin & 0.73 & Tianjin & 0.57 & Tianjin & 0.55 & Tianjin & 370.3 \\
\hline 4 & Tianjin & 0.01 & $\begin{array}{c}\text { Guangdon } \\
\text { g }\end{array}$ & 0.45 & Guangdong & 0.52 & Liaoning & 0.50 & $\begin{array}{c}\text { Guangdo } \\
\text { ng }\end{array}$ & 319.6 \\
\hline 5 & $\begin{array}{c}\text { Hei } \\
\text { longjiang }\end{array}$ & 0.01 & Liao ning & 0.36 & Zhejiang & 0.51 & Jilin & 0.48 & Jilin & 304.6 \\
\hline 6 & $\begin{array}{c}\text { Guangdo } \\
\text { ng }\end{array}$ & 0.08 & Jiang su & 0.35 & Liaoning & 0.50 & Guangdong & 0.48 & Liaoning & 302.9 \\
\hline 7 & Jiang su & 0.07 & Zhejiang & 0.25 & Jiang su & 0.49 & Zhejiang & 0.47 & Jiang su & 276.7 \\
\hline 8 & Liaoning & 0.07 & Shandong & 0.15 & Fu jian & 0.48 & Jiang su & 0.46 & Zhejiang & 267.4 \\
\hline 9 & Fu jian & 0.06 & Fu jian & 0.12 & Jilin & 0.44 & Fu jian & 0.45 & $\begin{array}{c}\text { Heilongji } \\
\text { ang }\end{array}$ & 245.6 \\
\hline 10 & Zhejiang & 0.05 & Jilin & 0.07 & Heilongjian & 0.43 & Heilongjiang & 0.43 & Fu jian & 236.3 \\
\hline 11 & Hubei & 0.05 & Hainan & -0.06 & Hainan & 0.43 & Hubei & 0.42 & Shandong & 172.1 \\
\hline 12 & Neimeng & 0.04 & Hubei & -0.07 & Hubei & 0.42 & Hainan & 0.42 & Hainan & 157.1 \\
\hline 13 & Shaanxi & 0.03 & Hebei & -0.08 & Shandong & 0.42 & Shandong & 0.41 & Hubei & 148.6 \\
\hline
\end{tabular}




\begin{tabular}{|c|c|c|c|c|c|c|c|c|c|c|}
\hline 14 & $\begin{array}{c}\text { Shandon } \\
\mathrm{g}\end{array}$ & 0.02 & $\begin{array}{c}\text { Heilongiia } \\
\text { ng }\end{array}$ & -0.08 & Chongqing & 0.42 & Neimenggu & 0.41 & $\begin{array}{c}\text { Neimeng } \\
\mathrm{gu}\end{array}$ & 138.2 \\
\hline 15 & Sichuan & -0.002 & $\begin{array}{c}\text { Chongqin } \\
\mathrm{g}\end{array}$ & -0.09 & Neimenggu & 0.42 & Chongqing & 0.40 & $\begin{array}{c}\text { Chongqin } \\
\mathrm{g}\end{array}$ & 118.6 \\
\hline 16 & $\begin{array}{c}\text { Chongqi } \\
\text { ng }\end{array}$ & -0.01 & Xinjiang & -0.12 & Sichuan & 0.41 & Jiangxi & 0.40 & Shaanxi & 105.6 \\
\hline 17 & Hunan & -0.02 & $\begin{array}{c}\text { Neimengg } \\
\mathrm{u}\end{array}$ & -0.16 & Jiangxi & 0.40 & Shaanxi & 0.39 & Sichuan & 87.5 \\
\hline 18 & Hebei & -0.02 & Shaanxi & -0.18 & Shanxi & 0.39 & Shanxi & 0.39 & Hebei & 86.6 \\
\hline 19 & Gansu & -0.03 & Ningxia & -0.19 & Xinjiang & 0.39 & Sichuan & 0.39 & Henan & 71.1 \\
\hline 20 & Anhui & -0.03 & Henan & -0.20 & Hebei & 0.38 & Hebei & 0.39 & Jiangxi & 63.3 \\
\hline 21 & Guizhou & -0.05 & Shanxi & -0.22 & Shaanxi & 0.38 & Hunan & 0.38 & Shanxi & 58.4 \\
\hline 22 & Shanxi & -0.06 & Jiangxi & -0.23 & Hunan & 0.38 & Henan & 0.38 & Hunan & 57.1 \\
\hline 23 & Henan & -0.06 & Hunan & -0.24 & Ningxia & 0.37 & Ningxia & 0.38 & Xinjiang & 54.6 \\
\hline 24 & Xinjiang & -0.08 & Sichuan & -0.28 & Henan & 0.37 & Xinjiang & 0.36 & Gansu & 39.3 \\
\hline 25 & Guangxi & -0.09 & Guangxi & -0.30 & Qinghai & 0.36 & Qinghai & 0.35 & Ningxia & 34.3 \\
\hline 26 & Hainan & -0.09 & Anhui & -0.30 & Anhui & 0.35 & Anhui & 0.35 & Anhui & 28.8 \\
\hline 27 & Qinghai & -0.09 & Qinghai & -0.42 & Guangxi & 0.33 & Guangxi & 0.35 & Guizhou & 25.9 \\
\hline 28 & Jiangxi & -0.11 & Gansu & -0.57 & Gansu & 0.31 & Gansu & 0.30 & Guangxi & 11.5 \\
\hline 29 & Ningxia & -0.13 & Yunnan & -0.59 & Guizhou & 0.30 & Yunnan & 0.29 & Qinghai & 10.4 \\
\hline 30 & Yunnan & -0.16 & Guizhou & -0.64 & Yunnan & 0.30 & Guizhou & 0.29 & Yunnan & 0.5 \\
\hline
\end{tabular}

Table 3 lists the four basic evaluation methods and the combination evaluation methods together for comparison. Taking Chongqing as an example, the comprehensive values of the four comprehensive evaluation methods are -0.01 , $0.09,0.42,0.40$, respectively, in the principal component analysis method, factor analysis method, entropy method and expert scoring method. The membership degree is $0.53,0.34,0.35$ and 1.57 respectively, the fuzzy frequencies are 0.34 , $0.22,0.23$ and 0.20 , respectively, and the rank scores are 105, 120,136,120, respectively, rank ranked 16,15,14,15, finally concluded that the fuzzy fuzzy Borda value of 118.6, ranked 15 ranking. It can be seen that the fuzzy Borda combination method can better reflect the results of the first four evaluation methods. From the blurred Borda integrated value, it can be seen that the comprehensive evaluation value of population development in the eastern provinces is higher than that in the central and western regions, and the future population development in the central and western regions is the focus of China's population strategy work, and its improvement can quickly improve the population development as a whole Level.

\section{Conclusing}

On the basis of reviewing the domestic and foreign papers on the comprehensive evaluation of population development, according to China's guiding ideology of population development strategy which is "stick to people-oriented,System innovation, give priority to investment in the comprehensive development of human beings, stabilize the low fertility level, improve the quality of the population, improve the population structure, guide the population reasonable distribution, guarantee the population security; realize the population change to the human capital power",this paper constructs the comprehensive evaluation index system of population development in China.They are the first index system of 3 ,the second index system of 8 , the third index system of 22;thr fourth index system of 42 . The principal component analysis method, the factor analysis method, the Entropy Weight Method and Expert Score Method have been selected in this paper, which includes both the objective analysis method and subjective analysis method.In order to overcome the inherent shortcomings of subjective analysis and objective analysis, the fuzzy Borda combination method is used to evaluate the four comprehensive evaluation methods, and a relatively reliable evaluation result is obtained.The results show that the comprehensive evaluation value of population development in the eastern provinces is higher than that in the central and western regions. In the evaluation of population self-development, the top ten are the eastern regions with the exception of Jilin, Heilongjiang and Shanxi. And the latter ten are mostly in the central and western regions. In the evaluation rankings of population and economic and social development, the eastern region is in the front and the central and western regions are backward; the central and western regions rank relatively higher in the evaluation of population and resources and environment.

\section{Acknowledgement}

This paper is supported by Chongqing Municipal Education Commission of Science and Technology Research Program (NO.KJ1404105). 


\section{References}

1. UNDP.Development of the Human Race 2010. UNDP (2010).

2. Ma Hongqi,The Index System and the Comprehensive Evaluation of China's Population Development.South China Population, 27, 3, 3-11(2009).

3. Chen Zhongchang, Model for Monitoring, Measuring and Evaluating Population Development and Its Application for 31 Chinese Provinces, Chinese Journal of Population Science,5, 72-79 (2007).

4. Chen Youhua, The Research on the Index Assess System of Population Modernization. Chinese Journal of Population Science,3,60-66(2003).

5. Hong Yingye,Scientific Development Perspective of Population and Resource Environment Coordinately Develop Research,Advances in Social Sciences, 1,31-36(2012).

6. Yang Yongjie, Exact algorithms for weighted and unweighted Borda manipulation problems, Theoretical Computer Science,3, (2016).

7. Liu Man, The Correctional Model of Population Development Equation, Modeling and Numerical Simulation of Material Science,3,139-141 (2013).

8. Nation Bureau of Statistics of China. China Statistical Yearbook 2014, China Statistics Press,(2014). 